\title{
Am phases in the matrix of a U-Pu-Zr alloy with Np, Am, and rare-earth elements
}

Dawn E. Janney ${ }^{\mathrm{a}}$, J. Rory Kennedy ${ }^{\mathrm{a}}$, James W. Madden ${ }^{\mathrm{a}}$, Thomas P. O’Holleran ${ }^{\mathrm{a}}$

addaho National Laboratory, Idaho Falls, ID 83415 USA

Corresponding author:

Dawn E. Janney

Idaho National Laboratory, Mail Stop 6188

Idaho Falls, ID 83415-6188

USA

Phone: 208-533-7478

Fax: 208-533-7863

E-mail: dawn.janney@inl.gov

Contact information for other authors: rory.kennedy@inl.gov, james.madden@inl.gov, thomas.oholleran@inl.gov

Manuscript submitted for publication in Journal of Nuclear Materials, April 21, 2014. Returned after revisions, August 19, 2014.

This manuscript has been authored by Battelle Energy Alliance, LLC under Contract No. DE-AC07-05ID14517 with the U.S. Department of Energy. The United States Government retains and the publisher, by accepting the article for publication, acknowledges that the United States Government retains a nonexclusive, paid-up, irrevocable, world-wide license to publish or reproduce the published form of this manuscript, or allow others to do so, for United States Government purposes.

\section{Page 1 of 22}




\title{
Am phases in the matrix of a U-Pu-Zr alloy with Np, Am, and rare-earth elements
}

Dawn E. Janney*, J. Rory Kennedy, James W. Madden, Thomas P. O’Holleran

Idaho National Laboratory, Idaho Falls, ID 83415

*To whom correspondence should be addressed. Phone 208-533-7478, fax: 208-533-7863, dawn.janney@inl.gov

\begin{abstract}
Phases and microstructures in the matrix of an as-cast U-Pu-Zr alloy with $3 \mathrm{wt} \% \mathrm{Am}, 2 \%$ $\mathrm{Np}$, and 8\% rare-earth elements were characterized by scanning and transmission electron microscopy. The matrix consists primarily of two phases, both of which contain Am: $\zeta-(\mathrm{U}, \mathrm{Np}$, $\mathrm{Pu}, \mathrm{Am})(\sim 70$ at $\%$ U, 5\% Np, 14\% Pu, 1\% Am, and 10\% Zr) and $\delta$-(U, Np, Pu, Am)Zr 2 ( 25\% U, 2\% Np, 10-15\% Pu, 1-2\% Am, and 55-60 at\% Zr). These phases are similar to those in U-PuZr alloys, although the $\mathrm{Zr}$ content in $\zeta_{-}(\mathrm{U}, \mathrm{Np}, \mathrm{Pu}, \mathrm{Am})$ is higher than that in $\zeta_{-}(\mathrm{U}, \mathrm{Pu})$ and the $\mathrm{Zr}$ content in $\delta$-(U, Np, $\mathrm{Pu}, \mathrm{Am}) \mathrm{Zr}_{2}$ is lower than that in $\delta-\mathrm{UZr}_{2}$. Nanocrystalline actinide oxides with structures similar to $\mathrm{UO}_{2}$ occurred in some areas, but may have formed by reactions with the atmosphere during sample handling.

Planar features consisting of a central zone of $\zeta-(\mathrm{U}, \mathrm{Np}, \mathrm{Pu}, \mathrm{Am})$ bracketed by zones of $\delta$-(U, Np, $\mathrm{Pu}, \mathrm{Am}) \mathrm{Zr}_{2}$ bound irregular polygons ranging in size from a few micrometers to a few tens of micrometers across. The rest of the matrix consists of elongated domains of $\zeta-(\mathrm{U}, \mathrm{Np}, \mathrm{Pu}$, $\mathrm{Am})$ and $\delta$-(U, Np, $\mathrm{Pu}, \mathrm{Am}) \mathrm{Zr}_{2}$. Each of these domains is a few tens of nanometers across and a few hundred nanometers long. The domains display strong preferred orientations involving areas a few hundred nanometers to a few micrometers across.
\end{abstract}




\section{Introduction}

Minor actinides (Np, Am, and $\mathrm{Cm}$ ) formed during irradiation of nuclear fuels are important contributors to the long-term hazards of nuclear waste. The FCRD and METAPHIX projects are currently pursuing one possible approach to decreasing long-term radiotoxicity from the minor actinides by incorporating them into U-Pu-Zr alloy fuels for transmutation (e.g.,[1-9]). The transmutation fuels are intended for reprocessing using a molten salt electrochemical process, which may leave low concentrations of rare-earth (RE) fission products in the recycled fuels (e.g., $[10,11])$.

Understanding irradiation-induced changes in U-Pu-Zr transmutation fuels requires accurate knowledge of the phases and microstructures in un-irradiated fuels. Characterizing Ambearing phases is particularly important because Am is easily lost during high-temperature processing (e.g., [12, 13]). Am-RE inclusions have been identified in a variety of alloys (e.g., [14-16]). X-ray maps showing variations in concentrations of Am adjacent to RE inclusions in as-cast U-Np-Pu-Am-Zr-RE alloys [17] suggest that the matrix may contain Am-bearing phases that do not have REs.

Previous attempts to characterize phases and microstructures in the matrix of as-cast UPu-Zr alloys using scanning electron microscope (SEM) analysis (e.g., [15, 17-19]) were unsuccessful because the alloys are too fine-grained. This paper uses transmission electron microscope (TEM) analysis to obtain images, single-crystal electron-diffraction patterns, and microchemical data from areas a few tens of nanometers to a few micrometers across from an alloy whose nominal composition is U-20Pu-3Am-2Np-8RE-15Zr (where RE is a rare-earth alloy of $6 \% \mathrm{La}, 16 \% \mathrm{Pr}, 25 \% \mathrm{Ce}$, and $53 \% \mathrm{Nd}$ and all proportions are specified by weight). The concentration of minor actinides in this alloy is comparable to that in fuels from the METAPHIX project (e.g., [2-5]) and to the alloys in which variations in concentrations of Am in the matrix 
were observed [17]. The concentration of REs is intended to approximate a transmutation fuel that has been previously reprocessed and irradiated to high burnup levels. Although techniques used to cast the sample are similar to those for fuel pins, no irradiation testing of this material was planned.

Because of the high spatial resolution of the TEM data, it was possible to identify and characterize individual matrix phases. Although TEM characterization techniques are commonly used in a wide variety of materials (e.g.,[20]), we believe this is the first time they have been applied to any Am alloy.

\section{Samples}

Approximately 10 grams of starting materials (U, Pu, previously prepared $\mathrm{Pu}-18 \mathrm{Am}$ alloy, Np, Zr, and previously prepared RE alloy) were arc-melted in an argon-atmosphere glovebox. The alloy was homogenized by melting it twice, inverting it before each melting. It was arc-melted a final time and cast in a fused silica tube with a nominal $4 \mathrm{~mm}$ inner diameter that had been previously prepared by applying a commercially available zirconia mold wash (suspension of zirconia in ethanol) to the inner surface of the mold with a swab. After casting, the alloy was allowed to cool rapidly to ambient temperature.

Chemical analyses were carried out to confirm the elemental composition of the alloy. Concentrations of Zr, La, Ce, Pr, Nd, Np, U, Pu-239, and Pu-240 were measured using inductively coupled plasma mass spectrometry (ICP-MS). Because the sample was not intended for irradiation, other Pu isotopes were not measured; however, Pu-239 and Pu-240 are estimated to represent about $90 \%$ of the total $\mathrm{Pu}$ based on analyses of other alloys using $\mathrm{Pu}$ from the same source. The concentration of Am was measured after chemical separation to eliminate possible isobaric effects from $\mathrm{Pu}-241$. 
The results of the chemical analyses are in Table 1 . They confirm that actual concentrations of all elements except Pu are within $1 \mathrm{wt} \%$ of nominal compositions, and the actual concentration of $\mathrm{Pu}$ is $\sim 80 \%$ of the nominal concentration. The analytical total is less than $100 \%$, but is consistent with the estimated 5\% measurement errors in individual analyses and the incomplete measurement of Pu. Some of the SEM and TEM data show locally significant concentrations of oxygen, which was not included in the chemical analyses; however, it is not clear whether the oxygen was part of the as-cast alloy or whether it was introduced during sample handling.

A sample was prepared for SEM analyses by embedding a transverse slice of the alloy in acrylic resin. Surface material was removed using progressively finer silicon-carbide papers (down to 1200 grit) with a water lubricant in an air-atmosphere glovebox. The sample was coated with a thin layer of sputtered metal before examination, but was not etched or electropolished.

Three TEM samples, each approximately $10 \mu \mathrm{m}$ square and $100 \mathrm{~nm}$ thick, were prepared from the SEM sample using a FEI Quanta 3D Dual Beam FEG Focused Ion Beam (FIB) instrument. Much of the material in each sample was too thick for optimum TEM analysis, and most of the data presented here are from thin areas a few micrometers across.

\section{Analysis methods}

SEM images were collected using a JEOL JSM 7000F field-emission SEM operating at a nominal accelerating voltage of $20 \mathrm{kV}$. Energy-dispersive X-ray (EDX) spectra were correlated with images to determine spatial distributions of elements. SEM-EDX spectra were not quantified because of limitations of the software in dealing with Am. 
TEM analyses used a JEOL 2010 transmission electron microscope operating at a nominal voltage of $200 \mathrm{kV}$. Images and diffraction patterns were collected with Gatan Digital Micrograph software. TEM-EDX spectra were collected with a Bruker 133 silicon-drift detector and quantified using Bruker software. Spectra were collected from areas several hundred nanometers across for comparison with results of the ICP-MS analyses, and from areas 15-30 nm across to measure compositions in specific locations.

Phases that produced single-crystal diffraction patterns were identified by comparing the experimental TEM-EDX data to annealed U-Pu-Zr alloys [19]. Identifications were checked by comparing the experimental diffraction patterns to simulated patterns from published crystal structures [21, 22] produced using JEMS software [23]. Phases producing rings in diffraction patterns were identified by comparing the experimental diffraction and TEM-EDX data to the International Centre for Diffraction Data's PDF4+ 2012 database.4. Results

\subsection{SEM and FIB data}

SEM images (e.g., Figures 1a and 1b) show a light-contrast matrix surrounding high-Zr and high-RE inclusions. SEM-EDX spectra show that some of the high-RE inclusions also contain significant concentrations of Am, and that the matrix contains $\mathrm{Zr}$ and actinides but not REs. Contrast variations on a scale of tens of nanometers in FIB images (e.g., Figures 1c and 1d) suggest that the matrix is nanocrystalline and contains more than one phase. However, the microstructure is too fine-grained to provide detailed information about individual phases.

Some SEM and FIB images show elongated features consisting of a light-contrast central zone bracketed by darker zones (e.g., Figures 1b-1d). These features bound irregularly shaped polygons a few tens of micrometers across. Variations in the widths and sharpness of the edges of the dark and light zones suggest that the features are planar, and are tilted at different orientations relative to the sample surface. 


\subsection{TEM data}

\subsubsection{Images}

TEM images (Figures 2 and 3) show that most of the matrix consists of dark and light domains a few tens of nanometers across and a few hundred nanometers long. Many of these domains are oriented approximately parallel to one of two perpendicular directions, forming strong local preferred orientation in areas that are hundreds of nanometers to micrometers across.

Some TEM images also show elongated features $~ 100-200 \mathrm{~nm}$ across and several micrometers long (e.g., Figures 2d, 3a-3c). Each of these features has a dark central zone bracketed by light zones. Images of the same areas produced by different instruments confirm that the large elongated features in the FIB, SEM, and TEM images are the same. (Mechanisms for forming image contrast differ between the instruments, and the light central stripes and dark edges of the linear features in the SEM and FIB images are consistent with dark central stripes and light edges in TEM images.)

$\mathrm{RE}$ inclusions located on the elongated features are associated with discontinuities in the dark central stripes of the features (Figures 3a, 3b). There is no obvious relationship between matrix microstructures and RE inclusions not located on elongated features (Figures 2b, 2c). High-Zr inclusions are commonly bordered by paired zones of dark and light matrix material, whether or not the inclusions are on elongated features (Figures 3c, 3d).

\subsubsection{TEM-EDX spectra}

Proportions of actinides and $\mathrm{Zr}$ in all but one of the TEM-EDX spectra from areas several hundred nanometers across (Figure 2, Table 2) are similar to those in the bulk sample (Table 1, atomic percentages without REs). None of the TEM-EDX spectra show RE elements or Si. One of the spectra shows a significant concentration of oxygen. 
TEM-EDX spectra from individual dark and light areas (Figure 3, Table 3) show that all four actinides are in both materials. Light areas have more Am than dark areas, and more $\mathrm{Zr}$ than U. With the exception of spectra from Area 1C3 (which have lower concentrations of actinides and $\mathrm{Zr}$ because of their high concentrations of $\mathrm{O}$ ), all of the spectra from the light material show similar compositions. In contrast, dark areas have more $\mathrm{U}, \mathrm{Pu}, \mathrm{Np}$, and $\mathrm{Zr}$ than light areas, and also have more $\mathrm{U}$ than $\mathrm{Zr}$ and wider variations in relative proportions of $\mathrm{U}$ and $\mathrm{Zr}$.

\subsubsection{TEM electron-diffraction data}

Figure 4 shows experimental and simulated electron-diffraction patterns from an

unusually large single crystal of dark material. These patterns are consistent with $\zeta-(\mathrm{U}, \mathrm{Pu})$. Closely spaced reflections correspond to large d-spacings that do not occur in $\delta-\mathrm{UZr}_{2}$.

Unfortunately, no comparable crystal of the light material could be found, although it is likely that diffraction patterns from the dark material also include reflections from adjacent light material. The reflections shown by the arrows in Figure $4 \mathrm{~g}$ are significantly more intense than those in the corresponding simulated $\zeta$-(U, Pu) diffraction pattern (Figure 4f), suggesting that these reflections may include diffracted intensity from both the dark and the light phases. The unusually intense reflections are consistent with $\delta-\mathrm{UZr}_{2}$ (Figure $4 \mathrm{~h}$ ).

In addition to sharp reflections, the experimental diffraction patterns have diffuse, discontinuous rings whose d-spacings correspond to high-intensity reflections from facecentered-cubic actinide oxides such as $\mathrm{UO}_{2}, \mathrm{NpO}_{2}, \mathrm{PuO}_{2}$, and $\mathrm{AmO}_{2}$.

\section{Discussion}

\subsection{Phase identification and characterization}

Three crystal structures were distinguished using electron-diffraction data, and TEM-

EDX spectra were collected from two materials identified in images. In combination, these data represent at least three phases: a dark phase with a structure similar to that of $\zeta-(\mathrm{U}, \mathrm{Pu})$, a light 
phase with a structure that is probably similar to that of $\delta-\mathrm{UZr}_{2}$, and at least one nanocrystalline actinide oxide with a structure similar to that of $\mathrm{UO}_{2}$. All four of the actinides are present in the dark and light phases, which can be identified as $\zeta_{-}(\mathrm{U}, \mathrm{Np}, \mathrm{Pu}, \mathrm{Am})$ and $\delta$-(U, Np, Pu, $\left.\mathrm{Am}\right) \mathrm{Zr}_{2}$ respectively. As there is no single-phase microchemical data from the nanocrystalline oxide, it is not possible to determine which actinides it contains.

Because of the fine-grained microstructure, the areas included in some of the individual TEM-EDX spectra are comparable to the widths of the dark and light domains. Variations in proportions of $\mathrm{U}$ and $\mathrm{Zr}$ in these spectra may indicate that each spectrum includes both dark and light materials, in different proportions. Only spectra from relatively large areas of dark material (1A2-6, 1A2-12, 1C3-7, 1C3-8, 1C3-10, and 1C3-DP) are likely to represent single phases, and all but one of these spectra (1C3-DP) is from the central stripe of an elongated feature. If it is assumed that all of the oxygen and a proportional amount of $\mathrm{U}$ are in $\mathrm{UO}_{2}$, the composition shown by these spectra is 70 at $\%$ U, $5 \% \mathrm{~Np}, 14 \% \mathrm{Pu}, 1 \% \mathrm{Am}$, and $10 \% \mathrm{Zr}$. (The assumption that the oxygen is in $\mathrm{UO}_{2}$ is for convenience; however, substituting other actinides in proportions similar to those in the bulk composition of the sample does not change the composition shown by spectra from the dark material significantly. $\mathrm{ZrO}_{2}$ is not considered here because there is no evidence for it in the diffraction patterns.)

The minimum concentration of $\mathrm{Zr}$ in spectra from the dark material in areas other than 1C3 is significantly above the maximum 5 at\% measured in $\zeta-(\mathrm{U}, \mathrm{Pu})$ in $\mathrm{U}-\mathrm{Pu}-\mathrm{Zr}$ alloys annealed at $590{ }^{\circ} \mathrm{C}$ (the lowest temperature for which there is published experimental data [19]). If the concentration of $\mathrm{Zr}$ increases with temperature in $\zeta-(\mathrm{U}, \mathrm{Np}, \mathrm{Pu}, \mathrm{Am})$ as it does in $\zeta-(\mathrm{U}, \mathrm{Pu})$ [19], the concentration of $\mathrm{Zr}$ in the experimental data may indicate that the composition of the 
dark matrix phase does not represent room-temperature equilibrium. Alternatively, it is possible that $\mathrm{Np}$ and Am increase the concentration of $\mathrm{Zr}$ in $\zeta-(\mathrm{U}, \mathrm{Np}, \mathrm{Pu}, \mathrm{Am})$ relative to $\zeta$-(U, Pu).

Spectra from the light phase in areas other than 1C3 consistently show 55-60 at\% Zr, $25 \% \mathrm{U}, 2 \% \mathrm{~Np}, 10-15 \% \mathrm{Pu}$, and 1-2\% Am. This concentration of $\mathrm{Zr}$ is somewhat lower than the $\sim 65-80$ at\% in $\delta-\mathrm{UZr}_{2}$ (e.g., [22, 24-26]), suggesting that some of the sites that are occupied by $\mathrm{Zr}$ in $\delta-\mathrm{UZr}_{2}$ may be occupied by actinides in $\delta$-(U, Np, Pu, Am) $\mathrm{Zr}_{2}$.

\subsection{Microstructure formation processes}

The qualitative absence of REs in SEM-EDX and TEM-EDX spectra from the matrix is consistent with other studies of U-Pu-Zr alloys with minor actinides and REs [14-16]. Binary U$\mathrm{RE}$ and Ce-Zr phase diagrams [27-31] suggest that the matrix formed from an actinide-Zr liquid that was immiscible with the liquid that formed the high-RE inclusions. There is no microstructural evidence for chemical reactions between the matrix and the high-RE inclusions at lower temperatures. Thus, it seems likely that microstructural evolution in the matrix was not influenced by the presence of the RE inclusions.

To our knowledge, there are no published phase diagrams that include U, Np, Pu, Am, and Zr. U-Pu-Zr phase diagrams (e.g., [19, 32]) indicate that the first phase to crystallize from a molten U-Pu-Zr alloy is a body-centered cubic solid solution commonly referred to as $\gamma-\mathrm{U}$. Subsolidus reactions lead to formation of $\zeta-(\mathrm{U}, \mathrm{Pu})$ at grain boundaries, followed by transformation of the remaining $\gamma-\mathrm{U}$ to a fine-grained intergrowth of $\zeta-(\mathrm{U}, \mathrm{Pu})$ and $\delta$-(U, $\mathrm{Pu}) \mathrm{Zr}_{2}$ [33].

Microstructures in the present sample are consistent with a similar series of transformations, with the elongated features forming along prior $\gamma-\mathrm{U}$ grain boundaries. The narrow parallel domains in the rest of the matrix suggest crystallographic relationships between $\zeta$-(U, Np, Pu, Am) and $\delta$ (U, Np, Pu, Am) Zr 2 . 
The extent to which Np can be incorporated into $\gamma$-U solid solutions is controversial: some researchers report limited miscibility between $\gamma$-U solid solutions and (body-centeredcubic) $\gamma$-Np in binary Np-Zr alloys [34, 35], while others report complete miscibility [36]. Although understanding relationships between $\gamma-(\mathrm{Np}, \mathrm{Zr})$ and $\gamma-(\mathrm{U}, \mathrm{Pu}, \mathrm{Zr})$ in room-temperature alloys is complicated by the likely existence of a solid solution between $\delta-\mathrm{NpZr}_{2}$ and $\delta-\mathrm{UZr}_{2}[34$, 36-38], nothing in the present data suggests the formation of separate Np phases at any temperature.

\section{Conclusions}

This paper identifies and characterizes Am phases in the matrix of an alloy with nominal composition 52U-20Pu-3Am-2Np-8.0RE-15Zr (where RE is a rare-earth alloy consisting of $6 \%$ La, 16\% Pr, 25\% Ce, and 53\% Nd and all proportions are by weight). The research combined SEM and FIB images with images, microchemical data, and single-crystal electron-diffraction data obtained using transmission electron microscopy. The high spatial resolution of the TEM data made it possible to determine the compositions and structures of individual phases for the first time.

The matrix consists primarily of two Am phases, which were identified as $\zeta-(\mathrm{U}, \mathrm{Np}, \mathrm{Pu}, \mathrm{Am})$ and $\delta$-(U, $\mathrm{Np}, \mathrm{Pu}, \mathrm{Am}) \mathrm{Zr}_{2}$ by analogy to U-Pu-Zr phase diagrams. Both phases occur in elongated domains a few tens of nanometers across and a few hundred nanometers long throughout most of the matrix. As a consequence of this geometry, excess free energies from phase boundaries are likely to be significantly larger than would be expected from randomly oriented isometric crystals. Individual domains display strong local preferred orientation, suggesting that kinetics of microstructural coarsening may be influenced by crystallographic relationships at phase boundaries. Both of these phenomena may require special consideration when modeling microstructural evolution during annealing and irradiation. 


\section{Acknowledgments}

We would like to thank the many people in the Nuclear Operations, Safeguards and Security, Radiological Safety, and Nuclear Science \& Technology organizations at Idaho National Laboratory who made it possible to carry this work out safely. FIB operations and electron microscopy were carried out in the Electron Microscopy Laboratory, Materials and Fuels Complex (MFC), INL. We thank the Analytical Laboratory at MFC for performing the bulk chemical analysis. We also thank Drs. Dennis D. Keiser, Jr., Steven L. Hayes, Jason M. Harp, and Melissa Teague for helpful discussions, and Dr. Brandon D. Miller for loading the TEM samples.

The research presented here was supported by the U.S. Department of Energy, Office of Nuclear Energy, under DOE Idaho Operations Office Contract DE-AC07-05ID14517. 


\section{References}

[1] W.J. Carmack, D.L. Porter, Y.I. Chang, S.L. Hayes, M.K. Meyer, D.E. Burkes, C.B. Lee, T. Mizuno, F. Delage, J. Somers, Metallic fuels for advanced reactors, Journal of Nuclear Materials, 392 (2009) 139-150.

[2] S. Brémier, P. Pöml, K. Inagaki, L. Capriotti, D. Papaioannou, V.V. Rondinella, H. Ohta, T. Ogata, Electron microprobe examination of metallic fuel for minor actinides transmutation in fast reactor, Transactions of the American Nuclear Society, 109 (2013) 616-619.

[3] D. Papaioannou, V.V. Rondinella, H. Ohta, T. Ogata, R. Nasirow, N. Niagolova, Irradiation effects on actinide containing U-Pu-Zr metallic fuels at several burnups, in: ANS Annual Conference, American Nuclear Society, Chicago, IL (June 24-28), 2012.

[4] V.V. Rondinella, H. Ohta, D. Papaioannou, T. Ogata, R. Nasyrow, T. Koyama, J.-P. Glatz, Characterization of metallic fuel for the transmutation of minor actinides in fast reactor, in: ANS Winter Conference, Washington, DC, American Nuclear Society, 2009.

[5] V.V. Rondinella, H. Ohta, D. Papaioannou, T. Ogata, D. Pellottiero, T. Koyama, J.-P. Glatz, Postirradiation examination of metallic fuel for minor actinides transmutation in fast reactor, in: ANS Annual Conference 2010, American Nuclear Society, San Diego, CA (June 13-17), 2010. [6] H. Ohta, T. Ogata, T. Yokoo, M. Ougier, J.-P. Glatz, B. Fontaine, L. Breton, Low-burnup irradiation behavior of fast reactor metal fuels containing minor actinides, Nuclear Technology, 165 (2009) 96-110.

[7] J.M. Harp, H.J.M. Chichester, Preliminary post irradiation examination of AFC-3A and AFC-3B, Transactions of the American Nuclear Society, 110 (2014).

[8] R.D. Mariani, D.L. Porter, S.L. Hayes, J.R. Kennedy, Metallic fuels: the EBR-II legacy and recent advances, Procedia Chemistry, 7 (2012) 513-520.

[9] D.D. Keiser, Jr., J.R. Kennedy, B.A. Hilton, S.L. Hayes, The development of metallic nuclear fuels for transmutation applications: materials challenges, JOM, 60 (2008) 29-32.

[10] C.E. Till, Y.I. Chang, W.H. Hannum, The integral fast reactor--an overview, Progress in Nuclear Energy, 31 (1997) 3-11.

[11] K. Kinoshita, T. Koyama, T. Inoue, M. Ougier, J.-P. Glatz, Separation of actinides from rare earth elements by means of molten salt electrorefining with anodic dissolution of U-Pu-Zr alloy fuel, Journal of Physics and Chemistry of Solids, 66 (2005) 619-624.

[12] D.E. Burkes, R.S. Fielding, D.L. Porter, Metallic fast reactor fuel fabrication for the global nuclear energy partnership, Journal of Nuclear Materials, 392 (2009) 158-163.

[13] C.L. Trybus, J.E. Sanecki, S.P. Henslee, Casting of metallic fuel containing minor actinide additions, Journal of Nuclear Materials, 204 (1993) 50-55.

[14] M. Kurata, T. Inoue, C. Sari, Redistribution behavior of various constituents in U-Pu-Zr alloy and U-Pu-Zr alloy containing minor actinides and rare earths in a temperature gradient, Journal of Nuclear Materials, 208 (1994) 144-158.

[15] T. Inoue, M. Kurata, L. Koch, J.C. Spirlet, C. Sari, Characterization of fuel alloys with minor actinides, in: E.L. Quinn, E.A. Blocher, R.W. Hess, I.O. Macke, E.M. Burke (Eds.) Transactions of the American Nuclear Society, American Nuclear Society, 1991. [16] C. Sari, C.T. Walker, M. Kurata, T. Inoue, Interaction of U-Pu-Zr alloys containing minor actinides and rare earths with stainless steel, Journal of Nuclear Materials, 208 (1994) 201-210. [17] D.E. Janney, J.R. Kennedy, As-cast microstructures in U-Pu-Np-Am-Zr alloy fuel pins with 5-8 wt\% minor actinides and 0-1.5 wt\% rare-earth elements, Materials Characterization, 61 (2010) 1194-1202. 
[18] J.I. Cole, D.D. Keiser, Jr., J.R. Kennedy, Microstructural characterization of cast metallic transmutation fuels, in: Global 2007, American Nuclear Society, Boise, ID, 2007.

[19] D.R. O'Boyle, A.E. Dwight, Uranium-plutonium-zirconium ternary alloy system, in:

Proceedings, 4th International Conference on Plutonium and Other Actinides, 1970, pp. 720-732.

[20] D.B. Williams, C.B. Carter, Transmission Electron Microscopy, 2 ed., Springer, New York, NY, 2009.

[21] A.C. Lawson, J.A. Goldstone, B. Cort, R.J. Martinez, F.A. Vigil, T.G. Zocco, J.W.

Richardson, Jr., M.H. Mueller, Structure of $\zeta$-phase plutonium-uranium, Acta Crystallographica, B52 (1996) 32-37.

[22] M. Akabori, A. Itoh, T. Ogawa, F. Kobayashi, Y. Suzuki, Stability and structure of the $\delta$ phase of the U-Zr alloys, Journal of Nuclear Materials, 188 (1992) 249-254.

[23] P. Stadelmann, jems (ems java version), in, CIME-EPFL, Lausanne, Switzerland, 2004.

[24] J.F. Duffey, C.A. Bruch, Delta phase field of the U-Zr equilibrium diagram, Transactions of the Metallurgical Society of AIME, (1958) 17-19.

[25] A.N. Holden, W.E. Seymour, Intermediate phase in the uranium-zirconium system, Journal of Metals, (1956) 1312-1316.

[26] R.I. Sheldon, D.E. Peterson, The U-Zr (uranium-zirconium) system, Bulletin of Alloy Phase Diagrams, 10 (1989) 165-171 and 205-206.

[27] H. Okamoto, Neodymium-uranium binary diagram, in: P. Villars, H. Okamoto, K. Cenzual

(Eds.) ASM Alloy Phase Diagram Database, ASM International, Materials Park, OH, 1990.

[28] H. Okamoto, Lanthanum-uranium binary diagram, in: P. Villars, H. Okamoto, K. Cenzual

(Eds.) ASM Alloy Phase Diagram Database, ASM International, Materials Park, OH, 1999.

[29] H. Okamoto, Cerium-uranium binary diagram, in: P. Villars, H. Okamoto, K. Cenzual

(Eds.) ASM Alloy Phase Diagram Database, ASM International, Materials Park, OH, 1990.

[30] M. Peatfield, Praseodymium-uranium binary diagram, in: P. Villars, H. Okamoto, K.

Cenzual (Eds.) ASM Alloy Phase Diagram Database, ASM International, Materials Park, OH, 1980.

[31] H. Okamoto, Cerium-zirconium binary diagram, in: P. Villars, H. Okamoto, K. Cenzual

(Eds.) ASM Alloy Phase Diagram Database, ASM International, Materials Park, OH, 1990.

[32] L. Leibowitz, E. Veleckis, R.A. Blomquist, A.D. Pelton, Solidus and liquidus temperatures

in the uranium-plutonium-zirconium system, Journal of Nuclear Materials, 154 (1988) 145-153.

[33] Y.H. Sohn, M.A. Dayananda, G.L. Hofman, R.V. Strain, S.L. Hayes, Analysis of

constituent redistribution in the $\gamma(\mathrm{bcc}) \mathrm{U}-\mathrm{Pu}-\mathrm{Zr}$ alloys under gradients of temperature and concentrations, Journal of Nuclear Materials, 279 (2000) 317-329.

[34] J.K. Gibson, R.G. Haire, Investigation of the neptunium-zirconium phase diagram by differential thermal analysis, Journal of Nuclear Materials, 201 (1993) 225-230.

[35] M. Kurata, T. Ogata, K. Nakamura, T. Ogawa, Thermodynamic assessment of the Fe-U, UZr, and Fe-U-Zr systems, Journal of Alloys and Compounds, 271-273 (1998) 636-640.

[36] R. Julián Rodríguez, C. Sari, A.J. Criado Portal, Investigation of the Np-Zr and U-Zr-Np systems, Journal of Alloys and Compounds, 209 (1994) 263-268.

[37] Y. Okamoto, R.G. Haire, J.K. Gibson, T. Ogawa, The investigation of selected Np-Zr alloys by X-ray diffraction up to $700^{\circ} \mathrm{C}$, Journal of Alloys and Compounds, 232 (1996) 302-306. [38] M.M. Gensini, R.G. Haire, J.K. Gibson, Investigation of the neptunium-zirconium system by X-ray diffraction, Journal of Alloys and Compounds, 213/214 (1994) 402-405. 


\section{Figures}
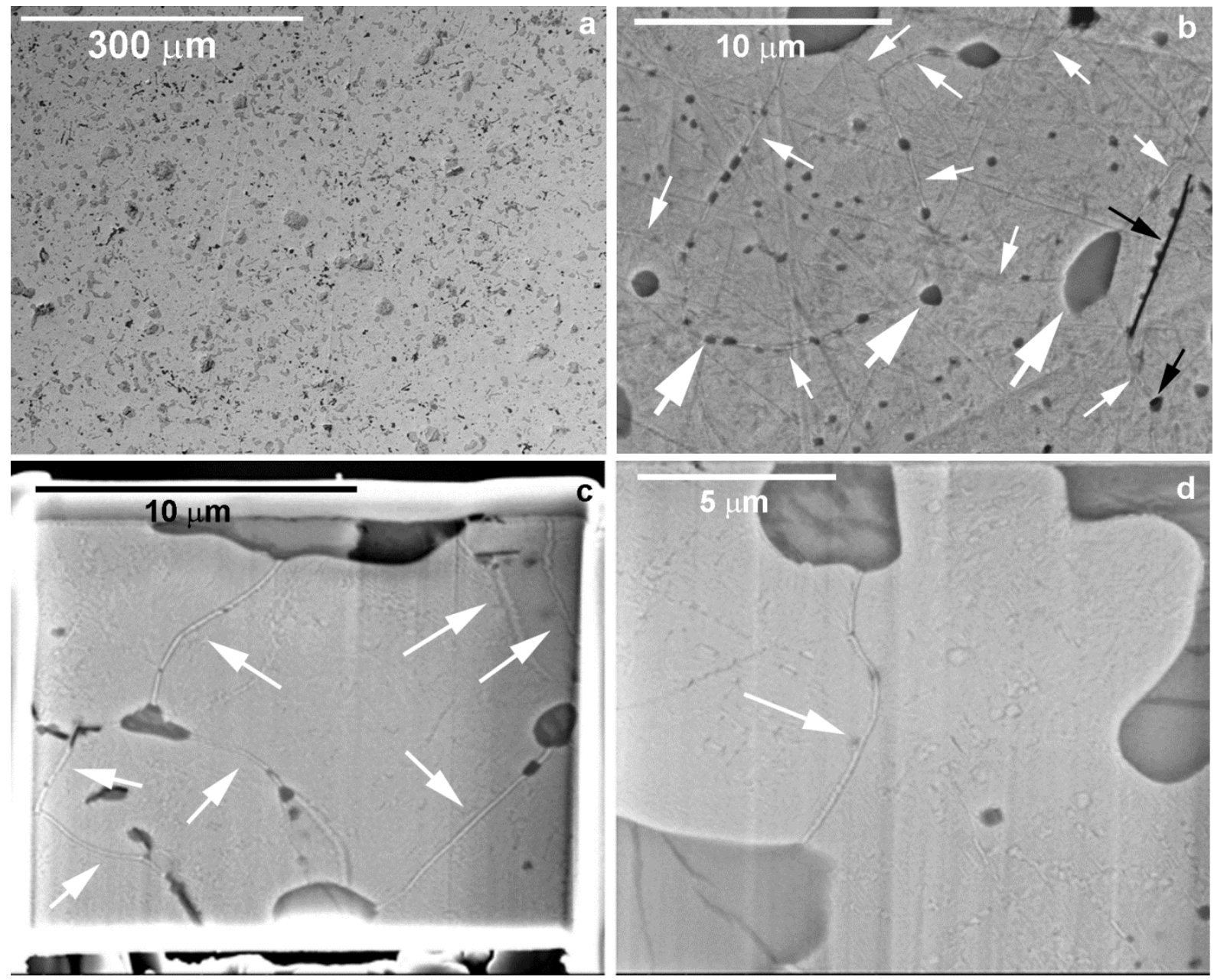

Figure 1: SEM and FIB images. a) Low-magnification back-scattered electron (BSE)

SEM image showing light-contrast matrix surrounding darker inclusions. b) Higher-

magnification BSE SEM image. Black arrows show high-Zr inclusions, large white arrows show high-RE inclusions, and small white arrows show elongated features. c and d) High-contrast secondary electron (SE) FIB images. Arrows show elongated features. 


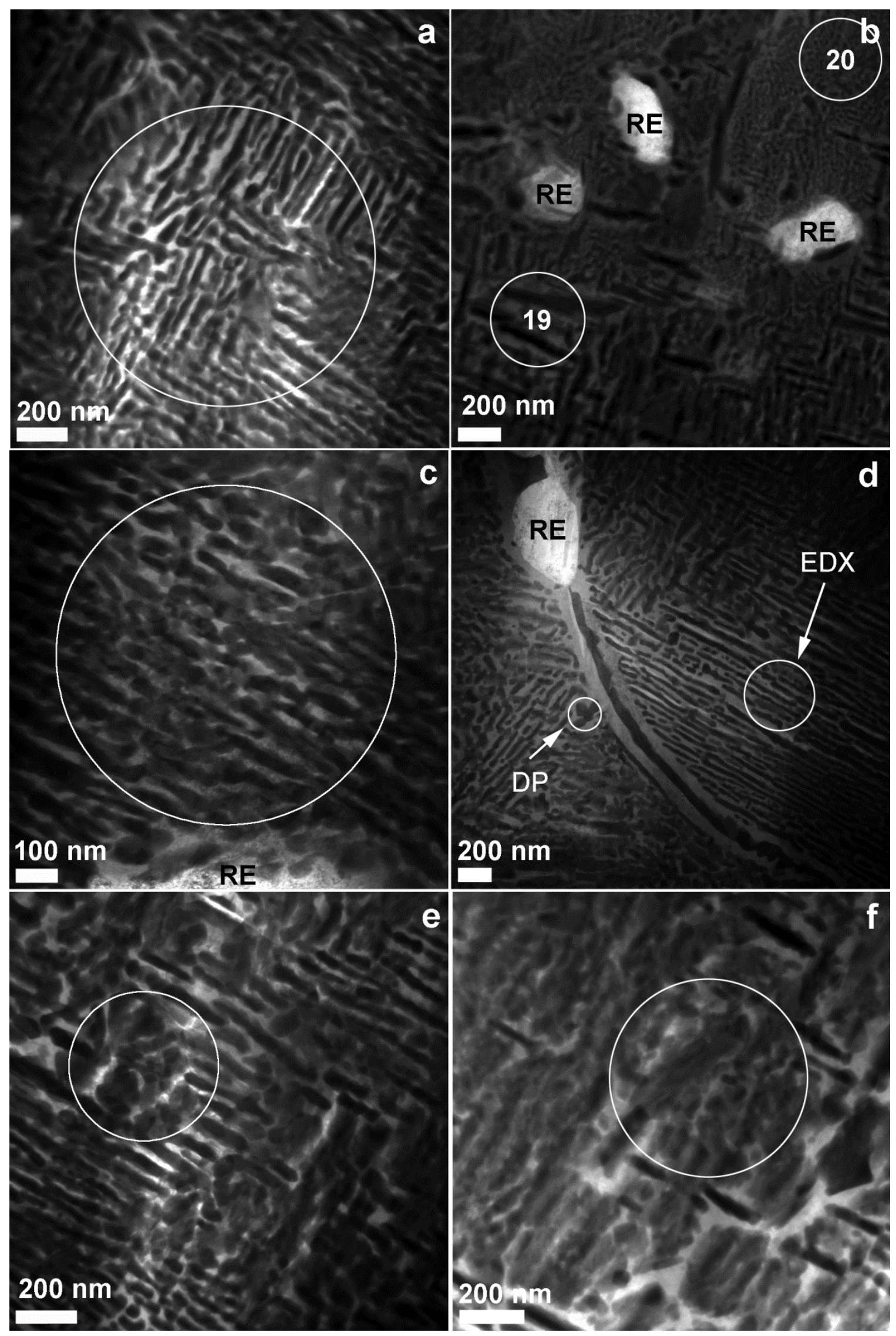

Page 16 of 22 
Figure 2: TEM images of the matrix. Circles in parts a, b, c, e, and f, and circle labeled “EDX” in part d indicate approximate locations measured by EDX spectra in Table 2. Circle labeled "DP" in part d shows the location of the diffraction patterns in Figure 4. "RE" indicates high-RE inclusions. 


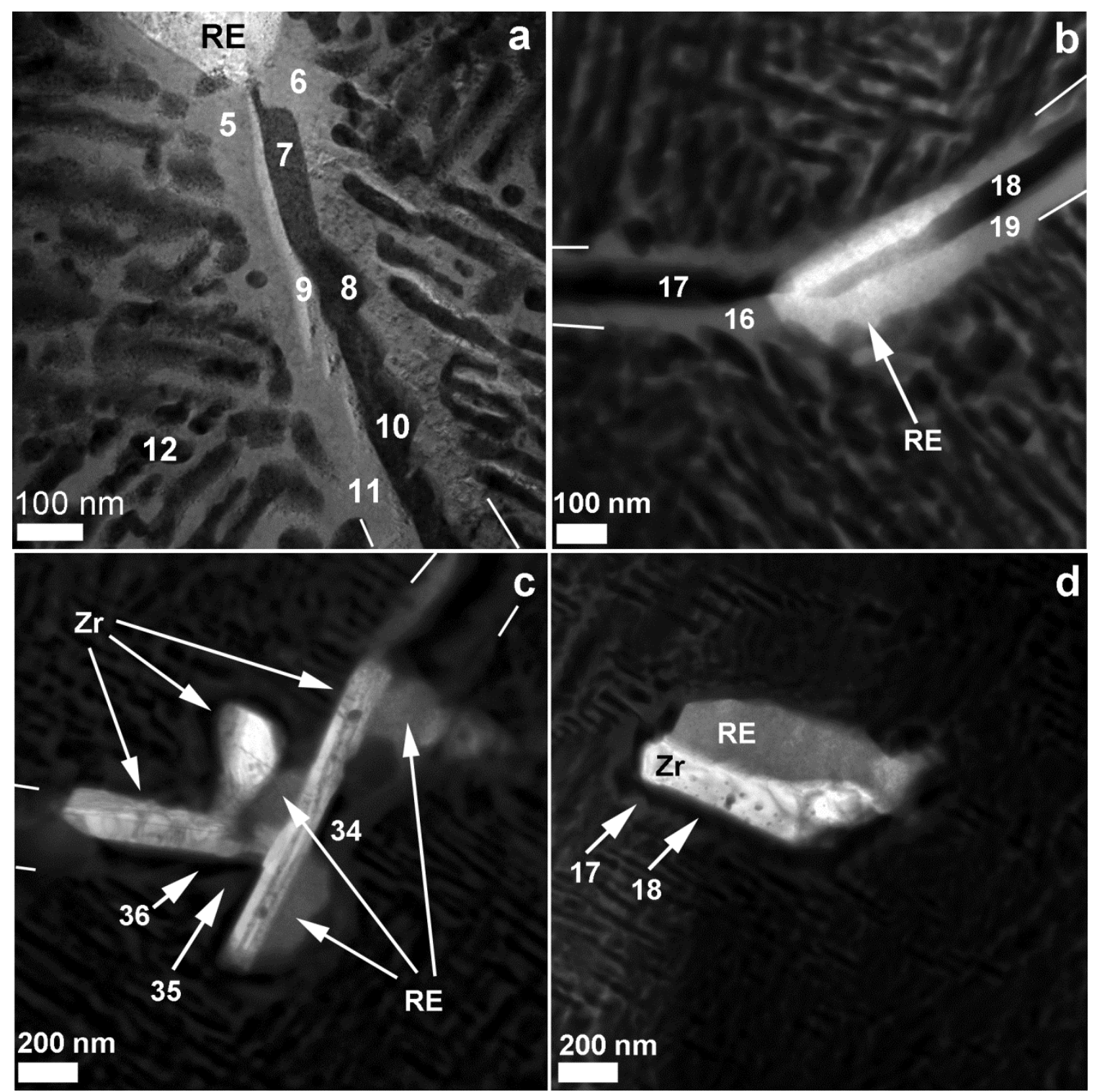

Figure 3: Locations of TEM-EDX spectra in Table 3. RE and Zr indicate high-RE and

high-Zr inclusions. Short white lines near edges of images indicate boundaries of elongated features. a) Higher-magnification view of the central portion of Figure 2d. b) Small high-RE inclusion overlapping a bend in an elongated feature. c, d) Inclusions with high-Zr and high-RE materials. 


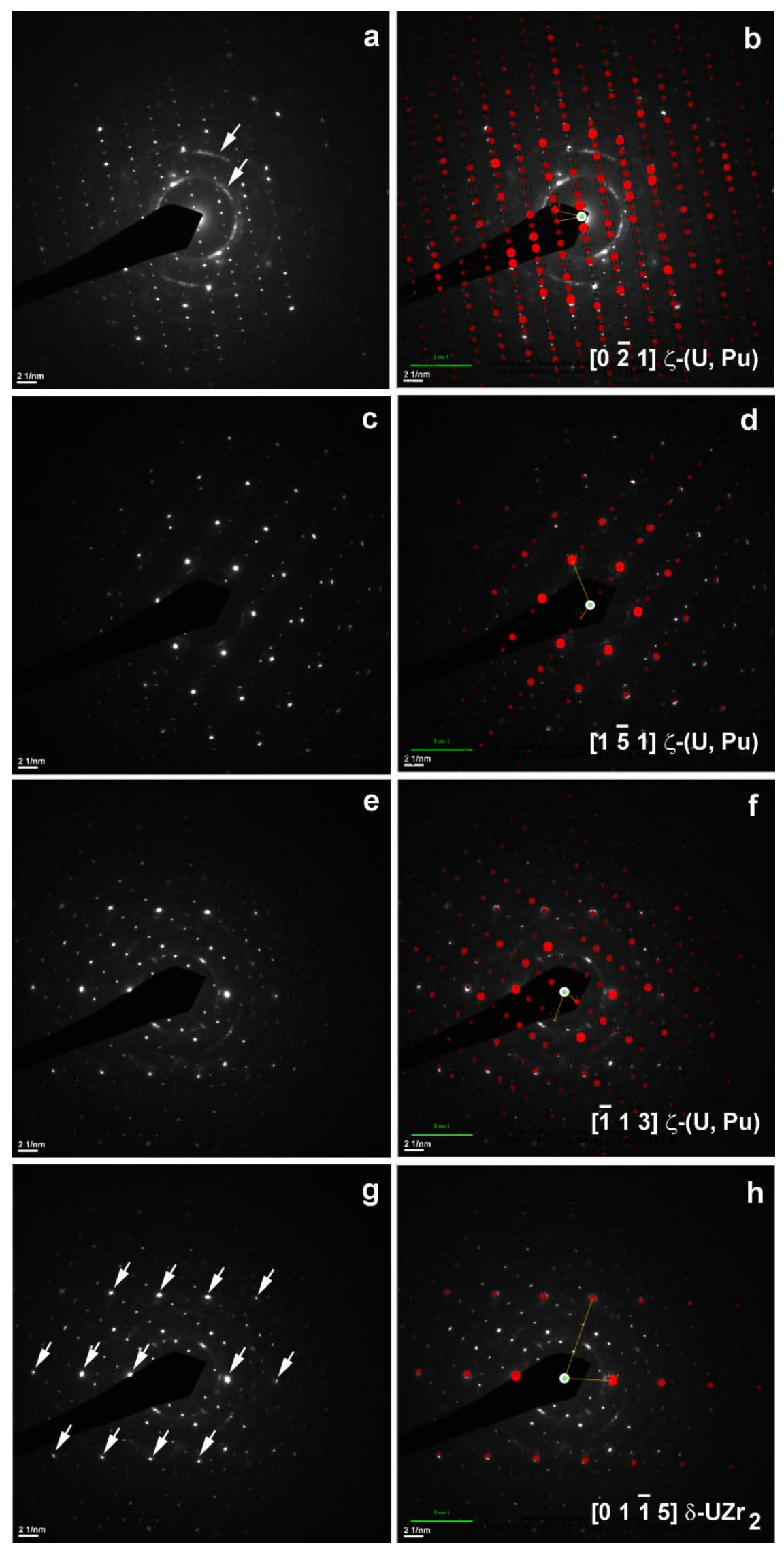

Page 19 of 22 
Figure 4: Experimental (left column) and simulated (right column) electron diffraction patterns from the area labeled "DP” in Figure 2d. Rings (e.g., at arrows in part a) are from nanocrystalline actinide oxides. Arrows in part g (which is otherwise identical to part e) show anomalously bright reflections matched by the simulated pattern in part h. 
Table 1: Chemical analyses of bulk sample

\begin{tabular}{rrrrr} 
Element & \multicolumn{2}{c}{ Wt\% } & At\% & $\begin{array}{r}\text { At\% } \\
\text { No REs }\end{array}$ \\
& Nominal & Actual & & N1.6 \\
$\mathrm{U}$ & 52 & 51.6 & 40.43 & 44.5 \\
$\mathrm{Pu}$ & 20 & $16.5^{\mathrm{a}}$ & 12.88 & 14.2 \\
$\mathrm{Am}$ & 3 & 3.74 & 2.89 & 3.2 \\
$\mathrm{~Np}$ & 2 & 2.54 & 2.00 & 2.2 \\
$\mathrm{Zr}$ & 15 & 15.9 & 32.59 & 35.9 \\
$\mathrm{Ce}$ & 2.00 & 1.64 & 2.18 & \\
$\mathrm{La}$ & 0.48 & 0.313 & 0.42 & \\
$\mathrm{Pr}$ & 1.28 & 0.717 & 0.95 & \\
$\mathrm{Nd}$ & 4.24 & 4.37 & 5.66 & \\
\hline RE Total & $\mathbf{8}$ & $\mathbf{7 . 0 4}$ & $\mathbf{9 . 2 1}$ & \\
Analytical total & $\mathbf{1 0 0 . 0 0}$ & $\mathbf{9 7 . 3 2}$ & $\mathbf{1 0 0 . 0 0}$ & $\mathbf{1 0 0 . 0}$ \\
a Pu-239 and Pu-240 & & & &
\end{tabular}

Table 2. Matrix composition (at\%) from large-area TEM-EDX spectra

\begin{tabular}{|c|c|c|c|c|c|c|c|}
\hline \multirow[b]{2}{*}{ Spectrum } & \multirow{2}{*}{$\begin{array}{c}\text { Image } \\
\text { (Figure 2) }\end{array}$} & \multicolumn{6}{|c|}{ At\% (normalized to $100 \%$ and rounded to closest $1 \%$ ) } \\
\hline & & $\mathbf{O}$ & $\mathrm{Zr}$ & $\mathbf{U}$ & Np & Pu & Am \\
\hline 1A matrix 1 & $\mathrm{a}$ & 0 & 35 & 44 & 5 & 14 & 2 \\
\hline 1A4-19 & b & 0 & 41 & 38 & 5 & 13 & 2 \\
\hline $1 \mathrm{~A} 4-20$ & b & 0 & 43 & 35 & 5 & 15 & 3 \\
\hline 1A matrix 2 & c & 1 & 30 & 49 & 5 & 14 & 1 \\
\hline $1 \mathrm{C}$ matrix 1 & $\mathrm{~d}$ & 8 & 34 & 40 & 4 & 13 & 2 \\
\hline $1 \mathrm{C}$ matrix 2 & e & 0 & 36 & 44 & 5 & 14 & 2 \\
\hline $1 \mathrm{C}$ matrix 3 & $\mathrm{f}$ & 0 & 39 & 40 & 5 & 14 & 3 \\
\hline
\end{tabular}


Table 3. Compositions from individual dark and light areas. Spectra from dark materials are in bold type and those from light materials are in italics. Horizontal lines separate data from different areas.

\begin{tabular}{|c|c|c|c|c|c|c|c|}
\hline \multirow[b]{2}{*}{ Spectrum } & \multirow{2}{*}{$\begin{array}{l}\text { Image } \\
\text { (Fig. 3) }\end{array}$} & \multicolumn{6}{|c|}{ At\% (normalized to $100 \%$ ) } \\
\hline & & $\mathbf{O}$ & $\mathrm{Zr}$ & $\mathbf{U}$ & Np & Pu & Am \\
\hline 1A2-6 & $--^{a}$ & 2 & 9 & 70 & 6 & 13 & 1 \\
\hline $1 A 2-8$ & $--^{a}$ & 1 & 61 & 23 & 2 & 11 & 2 \\
\hline $1 A 2-9$ & $--^{a}$ & 2 & 56 & 25 & 2 & 13 & 2 \\
\hline 1A2-10 & $--{ }^{b}$ & 3 & 12 & 66 & 6 & 14 & $\mathbf{0}$ \\
\hline 1A2-11 & $--{ }^{b}$ & 4 & 15 & 62 & 5 & 13 & 1 \\
\hline 1A2-12 & $--^{\mathrm{a}}$ & $\mathbf{0}$ & 12 & 69 & 5 & 13 & 1 \\
\hline $1 A 2-13$ & $--^{b}$ & 4 & 50 & 33 & 1 & 11 & 2 \\
\hline $1 C 3-5$ & $a$ & 36 & 39 & 17 & 1 & 6 & 1 \\
\hline $1 C 3-6$ & $a$ & 34 & 38 & 19 & 1 & 7 & 1 \\
\hline 1C3-7 & $\mathbf{a}$ & 23 & 5 & 58 & 4 & 9 & 1 \\
\hline 1C3-8 & $\mathbf{a}$ & 27 & 6 & 53 & 4 & $\mathbf{9}$ & $\mathbf{0}$ \\
\hline $1 C 3-9$ & $a$ & 35 & 38 & 17 & 2 & 8 & 1 \\
\hline 1C3-10 & $\mathbf{a}$ & 21 & 7 & 57 & 4 & 10 & $\mathbf{0}$ \\
\hline $1 C 3-11$ & $a$ & 23 & 47 & 18 & 1 & 9 & 1 \\
\hline 1C3-12 & $\mathbf{a}$ & 19 & 15 & 47 & 4 & 12 & 1 \\
\hline 1C3-DP & $--^{c}$ & 20 & 6 & 58 & 5 & 11 & 1 \\
\hline $1 A 3-16$ & $b$ & 0 & 59 & 25 & 2 & 12 & 2 \\
\hline 1A3-17 & b & o & 26 & 56 & 5 & 13 & 1 \\
\hline 1A3-18 & b & o & 14 & 68 & 5 & 13 & 1 \\
\hline $1 A 3-19$ & $b$ & 0 & 63 & 22 & 2 & 12 & 2 \\
\hline $1 C 7-34$ & C & 0 & 59 & 25 & 2 & 12 & 2 \\
\hline 1C7-35 & C & 0 & 52 & 30 & 2 & 13 & 1 \\
\hline 1C7-36 & C & 2 & 25 & 55 & 4 & 12 & 1 \\
\hline $1 C 5-17$ & $d$ & 0 & 60 & 24 & 2 & 13 & 2 \\
\hline 1C5-18 & d & o & 33 & 52 & 4 & 11 & $\mathbf{0}$ \\
\hline
\end{tabular}

${ }^{\mathrm{a}}$ From continuation of elongated feature beyond right edge of Figure $3 \mathrm{~b}$

${ }^{\mathrm{b}}$ Close to (but not part of) continuation of elongated feature beyond right edge of Figure $3 \mathrm{~b}$

'From dark material in area labeled “DP,” Figure 2d 